\title{
Use of soft contact lenses in an eye casualty department for the primary treatment of traumatic corneal abrasions
}

\author{
J F ACHESON, J JOSEPH, AND D J SPALTON \\ From the Department of Ophthalmology, St Thomas's Hospital, London SE1 7EH
}

SUMmARY We have assessed the role of bandage contact lenses in the primary treatment of traumatic corneal abrasions. Patients treated with bandage lenses healed more quickly $(0 \cdot 05>p>0.02)$ and with less discomfort $(0.05>p>0.02)$ than those treated traditionally, with the added advantage of maintaining vision during treatment. Resterilisation of contact lenses reduces the cost and makes the treatment economically viable. Large diameter lenses were fitted satisfactorily without the use of keratometry.

Traumatic corneal abrasions represent a substantial proportion of the problems presenting to the eye casualty department. In a recent three-month period at St Thomas's Hospital $120(11 \%)$ out of 1086 new patients were treated for this common problem. Chiapella and Rosenthal' have recently reported a similar frequency of $848(12.9 \%)$ out of 6576 patients seen in a year at Leicester Royal Infirmary. Each patient with this injury suffers marked short term discomfort and visual disability.

Traditionally the management of corneal abrasions consists of topical mydriatics, antibiotics, and pad and bandage. The healing period may last for several days and is associated with continuing pain and further visual disability from the dressing. Alternatively, ocular surface abnormalities can be successfully treated with bandage contact lenses, achieving the goals of pain reduction, facilitation epithelial healing, and proper surface hydration. ${ }^{2}$ Moreover, visual function is retained. The secondary use of such lenses has been reported in cases of delayed healing of corneal abrasions or where damage to the basement membrane and Bowman's layer is associated with epithelial instability and recurrent erosions. ${ }^{2}$ There have been no reported trials of the use of bandage lenses in the primary management of corneal abrasions, and this study sets out to show that patients with large surface area losses $\left(>4 \mathrm{~mm}^{2}\right)$ may benefit from this approach.

Correspondence to D J Spalton.

\section{Material and methods}

All patients seen in the eye casualty department at $\mathrm{St}$ Thomas's Hospital between 7 February and 20 July 1985 were considered. Twenty eight patients with traumatic abrasions were entered in a randomised controlled trial after fulfilling the following criteria: the abrasion was of a surface area of greater than $4 \mathrm{~mm}^{2}$, the patient was over 18 years and under 65 years old, there was no evidence of secondary infection or retained foreign body or coincidental ocular pathology, and no previous treatment had been given. The area of abrasion was measured by the slit-lamp gated beam. No assessment of basement membrane damage was made.

Suitable patients were randomly allocated into one of two treatment groups: (a) occlusive pad and bandage, $(b)$ bandage contact lens. All patients received guttae chloramphenicol $0.5 \%$ and homatropine $2 \%$. Focus $800 \cdot 16 \mathrm{~mm}$ centre thickness, $8 \cdot 6$ $\mathrm{mm}$ back central optic radius, $14.5 \mathrm{~mm}$ diameter, $80 \%$ water plano hydrophilic contact lenses were

VISUAL ANALOGUE PAIN SCORE

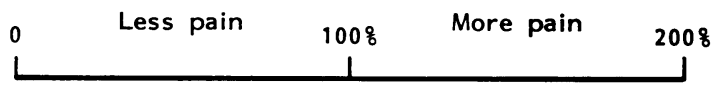

Fig. 1 Patients were shown this figure and they marked the percentage of their pretreatment pain that they experienced after one day. 
Table 1 Patients treated with pad and bandage

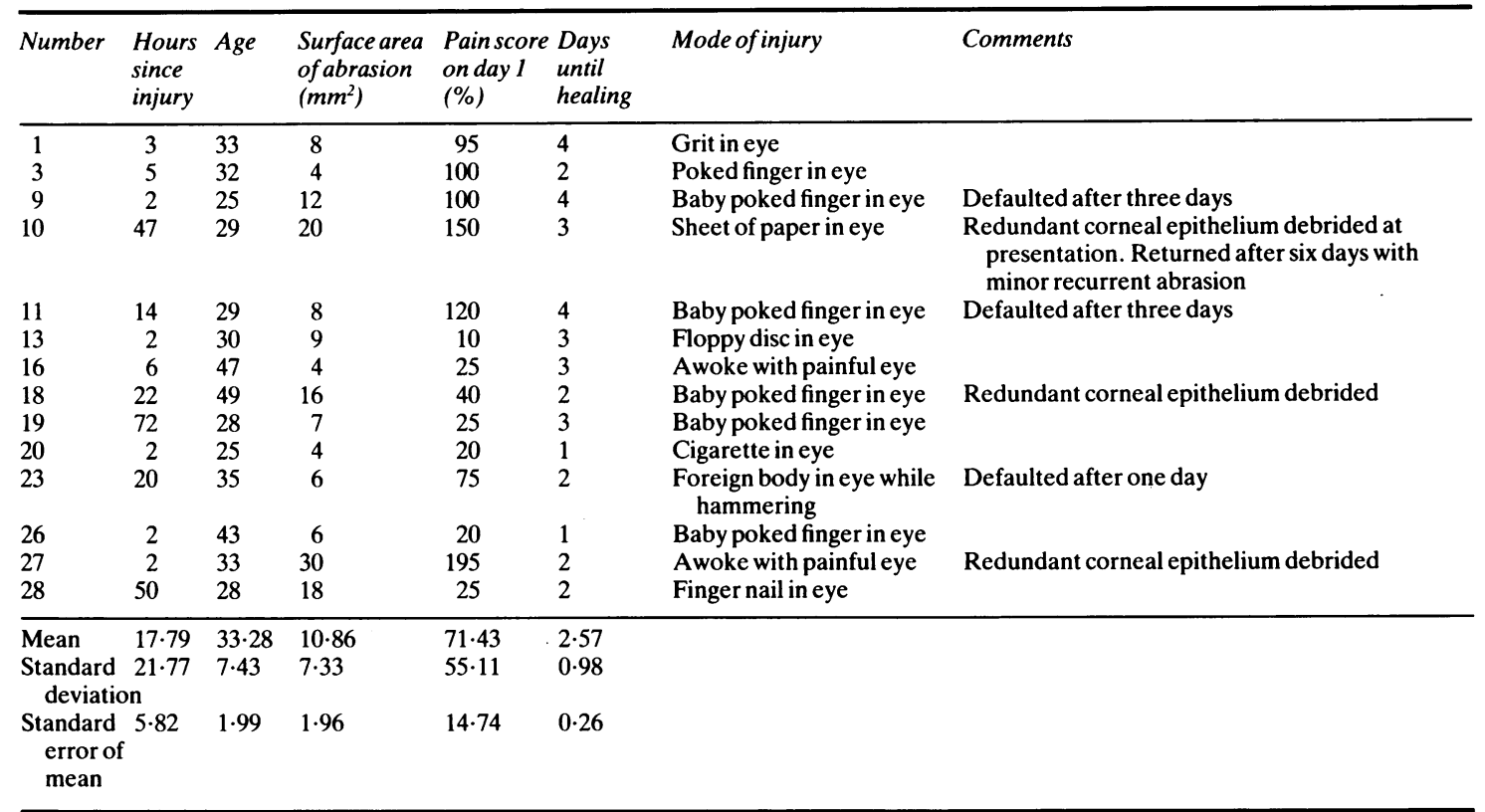

used. They were applied without preliminary keratometry. The patients were reviewed daily and the abrasions considered healed when local punctate keratitis only could be observed on slit-lamp biomicroscopy of the injured site. Each day the patients made an assessment of their pain on a visual analogue scale (Fig. 1).

\section{Results}

These are summarised on Tables 1,2, and 3, and in Figs. 2 and 3 . The groups were compared by a twotailed Student's $t$ test. The patients in each treatment group were comparable with respect to age, time elapsed since injury, and size of abrasion $(0.05>p>0 \cdot 1)$. Those treated with a bandage lens noted less pain after 24 hours than those treated with a pad and bandage $(0.05>p>0.02)$. They also reached the healing point more quickly $(0.05>p>0.02)$. In the contact lens group patient no. 6 could not tolerate a lens for more than 24 hours, by which time the abrasion had virtually healed, and had to be changed to a pad and bandage. Patient no. 8 went for six days without reattending and has been excluded from the analysis.

In the pad and bandage treatment group patients 9 , 11 , and 23 all failed to attend for final review and discharge after daily attendances while the abrasions remained unhealed. It is assumed that these lesions had healed by the following day, but they might in fact have taken rather longer. In that case the difference between the average healing times of the two groups would have been more marked.

\section{Discussion}

After corneal epithelial injury there is a cellular response within 1-5 hours leading to infiltration by polymorphonuclear leucocytes and macrophages. The adjacent epithelium undergoes amoeboid transformation and cell division, and the defect may be covered within 24-48 hours. Epithelial stability requires the presence of an intact basement membrane, proper surface hydration, an absence of secondary infection, normal precorneal tear film function, and protection from further lid induced trauma during blinking. ${ }^{23}$ Soft bandage contact lenses may offer these conditions more reliably than an occlusive dressing, just as they have already been shown to be helpful in the management of many corneal surface diseases and certain penetrating injuries. $^{2-5}$ However, Williams and Buckley have recently shown bandage lenses to be singularly unhelpful and possibly detrimental when compared with the topical application of oculentum simplex in the management of recurrent corneal erosions in map-dot-fingerprint dystrophy, ${ }^{6}$ but they also suggest that trauma is of little importance in the production of erosions in this condition.

The study suggests that the primary treatment of 
Table 2 Patients treated with bandage contact lens

\begin{tabular}{|c|c|c|c|c|c|c|c|}
\hline Number & $\begin{array}{l}\text { Hours } \\
\text { since } \\
\text { injury }\end{array}$ & Age & $\begin{array}{l}\text { Surface area } \\
\text { of abrasion } \\
\left(\mathrm{mm}^{2}\right)\end{array}$ & $\begin{array}{l}\text { Pain score } \\
\text { on day } 1 \\
(\%)\end{array}$ & $\begin{array}{l}\text { Days } \\
\text { until } \\
\text { healing }\end{array}$ & Mode of injury & Comments \\
\hline 2 & 0.75 & 27 & 8 & 25 & 2 & Radio aerial in eye & \\
\hline 4 & 2 & 51 & 20 & 10 & 1 & Punched in eye & \\
\hline 5 & 14 & 32 & 12 & 15 & 2 & Fell off motorcycle & \\
\hline 6 & 11 & 28 & 34 & 75 & 3 & Taking off makeup & $\begin{array}{l}\text { Unable to tolerate bandage contact lens in spite } \\
\text { of cornea virtually healing in one day; changed } \\
\text { to chloramphenicol eye ointment and pad }\end{array}$ \\
\hline 7 & 14 & 25 & 5 & 70 & 2 & Foreign body hitting eye & \\
\hline 8 & 29 & 67 & 6 & $?$ & $?$ & Foreign body hitting eye & $\begin{array}{l}\text { Failed to attend until telephoned and requested } \\
\text { to return to casualty department }\end{array}$ \\
\hline 12 & 4 & 22 & 4 & 40 & 2 & Plant leaf in eye & \\
\hline 14 & $4 \cdot 5$ & 76 & 48 & 30 & 2 & $\begin{array}{l}\text { Tear ducts syringed } \\
\text { earlier in the day }\end{array}$ & Returned the next day with a recurrent abrasion \\
\hline 15 & 12 & 26 & 8 & 20 & 2 & Punched in eye & $\begin{array}{l}\text { Redundant corneal epithelium debrided before } \\
\text { lens applied }\end{array}$ \\
\hline 17 & 29 & 36 & 4 & 10 & 1 & Unknown & \\
\hline 21 & 4 & 44 & 28 & 10 & 2 & Foreign body hitting eye & \\
\hline 22 & 23 & 33 & 9 & 50 & 2 & $\begin{array}{l}\text { Scratched in eye by dog's } \\
\text { claw }\end{array}$ & $\begin{array}{l}\text { Returned after two weeks with a minor recurrent } \\
\text { corneal abrasion }\end{array}$ \\
\hline 24 & 26 & 42 & 16 & 50 & 1 & Plaster in eye & \\
\hline 25 & 10 & 27 & 4 & 30 & 2 & Pencil poked in eye & \\
\hline Mean 1 & $12 \cdot 95$ & $38 \cdot 28$ & $14 \cdot 71$ & 33.46 & $1 \cdot 85$ & & . \\
\hline $\begin{array}{l}\text { Standard } \\
\text { deviation }\end{array}$ & $\mathrm{n}^{9 \cdot 46}$ & $15 \cdot 77$ & $12 \cdot 90$ & $21 \cdot 34$ & 0.53 & & \\
\hline $\begin{array}{l}\text { Standard } \\
\text { error of } \\
\text { mean }\end{array}$ & $2 \cdot 53$ & $4 \cdot 22$ & $3 \cdot 45$ & $\begin{array}{l}5 \cdot 71 \\
(n=13)\end{array}$ & $\begin{array}{l}0 \cdot 14 \\
(n=13)\end{array}$ & & \\
\hline
\end{tabular}

traumatic corneal abrasions with soft contact lenses has an apparent advantage over the traditional occlusion in terms of reduced pain during healing and speedier healing. To this can be added the further advantage of faster rehabilitation; four of our patients were able to return to work with their lenses in situ. Possible disadvantages are seen from the patient who defaulted from follow-up with a contact

Table 3 Statistical analysis of the results for the two treatment groups

\begin{tabular}{|c|c|c|c|c|c|c|}
\hline & \multicolumn{2}{|c|}{$\begin{array}{l}\text { Patients treated } \\
\text { with pad }+ \\
\text { bandage }\end{array}$} & \multicolumn{2}{|c|}{$\begin{array}{l}\text { Patients treated } \\
\text { with bandage } \\
\text { contact lens }\end{array}$} & \multirow[t]{2}{*}{$t$} & \multirow[t]{2}{*}{$p$} \\
\hline & Mean & $\begin{array}{l}\text { Standard } \\
\text { deviation }\end{array}$ & Mean & $\begin{array}{l}\text { Standard } \\
\text { deviation }\end{array}$ & & \\
\hline $\begin{array}{l}\text { Hours since } \\
\text { injury }\end{array}$ & $17 \cdot 79$ & $21 \cdot 77$ & 12.95 & 9.46 & 0.76 & $\begin{array}{l}\text { Not } \\
\text { significant }\end{array}$ \\
\hline Age & $33 \cdot 28$ & $7 \cdot 43$ & $38 \cdot 28$ & $15 \cdot 77$ & $1 \cdot 07$ & $0.5>p>0.1$ \\
\hline $\begin{array}{l}\text { Surface area } \\
\text { of abrasion }\end{array}$ & $10 \cdot 86$ & $7 \cdot 33$ & $14 \cdot 71$ & $12 \cdot 90$ & 0.97 & $0.5>p>0.1$ \\
\hline $\begin{array}{l}\text { Pain score } \\
\text { after } 24 \mathrm{~h} \text { of } \\
\text { treatment }\end{array}$ & $71 \cdot 43$ & $55 \cdot 11$ & 33.46 & $21 \cdot 34$ & $2 \cdot 39$ & $0.05>p>0.02$ \\
\hline $\begin{array}{l}\text { Days until } \\
\text { healing }\end{array}$ & $2 \cdot 57$ & 0.98 & $1 \cdot 85$ & 0.53 & $2 \cdot 40$ & $0.05>p>0.02$ \\
\hline
\end{tabular}

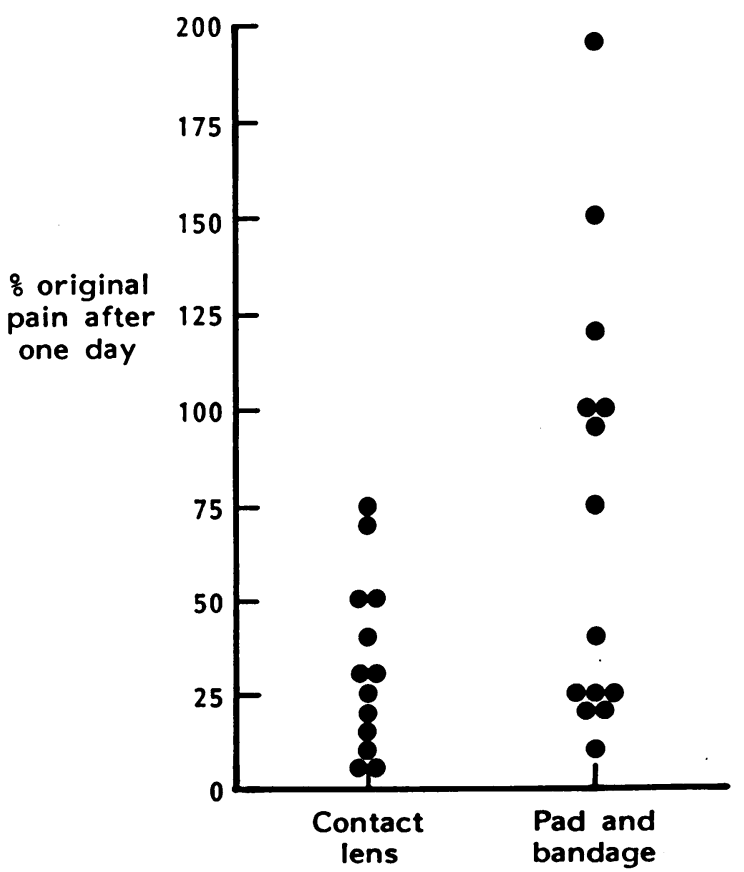

Fig. 2 Pain score after one day. 


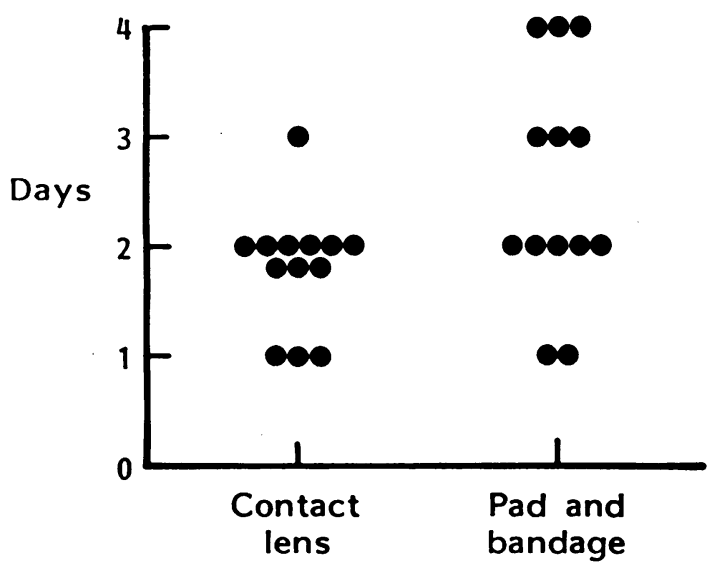

Fig. 3 Number of days until healing.

lens fitted (no.8). In this case there was no problem when he was seen and the lens removed six days later. However, the complications of prolonged usage are well known, and a patient who absconds with a lens in place may be at some risk. ${ }^{27}$ In a series of 322 cases of ulcerative keratitis $56(17 \%)$ were associated with the use of contact lenses, and of these $86 \%$ were soft lenses for the correction of ametropia. ${ }^{8}$ Soft contact lenses are an important risk factor for the development of infected corneal ulcers, but traumatic abrasions are also a risk factor, and we believe that with properly sterilised and fitted bandage lenses, and with the use of a prophylactic broad spectrum antibiotic, the risks are minimal over such a short period of time. In most patients the abrasion healed within two days, after which the lens was removed.

The study further shows that fitting a bandage lens without complication can be undertaken by ophthalmic casualty medical staff without the use of keratometry or special training, provided a large back optic radius lens is used. The availability of a keratometer and specialised contact lens experience is beyond the scope of a routine ophthalmic casualty service. We explicitly set out to show that, with a careful choice of suitable lens and a clinical check for fit at the time of application, followed by short term therapeutic use, keratometry is unnecessary. Our findings bear this out, as poor fit was not a practical problem.

A further potential problem with bandage lenses is that of corneal hypoxia. The partial pressure of oxygen in the precorneal tear film is about $155 \mathrm{mmHg}$ with the eyes open and falls to $55 \mathrm{mmHg}$ on eyelid closure. ${ }^{9}{ }^{10}$ It falls further when the lids are closed and a soft lens is in place, to a level of $23 \mathrm{mmHg}$ or below, and clinically significant corneal hypoxia may result. ${ }^{910}$ It has been held that even lenses with a high oxygen permeability $\left\{\right.$ DK of over $40\left(\mathrm{~cm}^{2} / \mathrm{s}\right)(\mathrm{m} 102 / \mathrm{ml}$ $\left.\times \mathrm{mmHg}) \times 10^{-11}\left(35^{\circ} \mathrm{C}\right)\right\}$ and low centre thickness may approach this threshold. The Focus 80 lens has a DK of $48.6\left(\mathrm{~cm}^{2} / \mathrm{s}\right)(\mathrm{m} 102 / \mathrm{ml} \times \mathrm{mmHg}) \times 10^{-11}\left(35^{\circ} \mathrm{C}\right)$ and a centre thickness of $0.16 \mathrm{~mm} .{ }^{11}$ No problems of corneal oedema were observed in our patients and the risk of corneal hypoxia does not appear to be important. This is reflected in the increased healing of the abrasion in the soft lens group, possibly because these patients have greater oxygen exposure during the day, when their eyes are open, than those in the pad and bandage group, who may be relatively hypoxic all the time.

Limitations of the use of such treatment are the obvious ones of expense and availability of lenses. Each bandage lens costs $£ 15$ to the NHS compared with about $£ 3$ for three days' treatment with a pad and bandage. However, this is offset by the facts that these lenses may be resterilised either by heat or chemically," and that fewer casualty attendances may be required of the patient and of the department's resources, so that the treatment may be more economical.

The limitations of this study are the relatively small number of patients, the four patients who failed to observe the follow-up protocol, the lack of data on the condition of the basement membrane and Bowman's layer at the time of initial assessment, and the lack of long-term follow-up to assess the problem of recurrent abrasions. Brown and Bron, ${ }^{12}$ reviewing recurrent erosions, found a history of trauma in $56 \%$ of 80 patients, $65 \%$ of which occurred within four months of the original injury. However, no one to our knowledge has investigated prospectively the impact of primary treatment on this complication. We found that in the contact lens group two patients returned shortly after the healing point with recurrent erosions, one after only 24 hours and the other after 14 days. No such problems were noted with the pad and bandage group. We conclude that the results support the hypothesis that bandage contact lenses used in the primary treatment of traumatic corneal abrasions offer certain advantages over conventional treatment, namely a faster and more comfortable healing period at a reasonable economic cost.

We thank Mr M G Falcon for his advice during the preparation of this manuscript.

\section{References}

1 Chiapella AP, Rosenthal AR. One year in an eye casualty. Br J Ophthalmol 1985; 69: 865-70.

2 Throft RA. Therapeutic soft contact lenses. The cornea: scientific foundations and clinical practice. Boston: Little, Brown, 1983: 430-84.

3 Yanoff M, Fine BS. Ocular pathology. 2nd ed. Philadelphia: Harper and Row, 1982: 132-6. 
4 Hick G, Konen W, Klip H. Lamellar or penetrating injuries of the cornea and their treatment by contact lenses. Fortschr Ophthalmol 1984; 91: 32-4.

5 Morrison R, Shovlin JP. A review of the use of bandage contact lenses. Metab Pediatr Syst Ophthalmol 1982; 6: 117-21.

6 Williams R. Buckley R. Pathogenesis and treatment of recurrent erosion. BrJ Ophthalmol 1985; 69: 435-7.

7 Hovding G. Hydrophilic contact lenses in corneal disturbances. Acta Ophthalmol (Kbh) 1984; 62: 566-76.

8 Galentine PG, Cohen EJ, Laibson PR, et al. Corneal ulcers associated with contact lens wear. Arch Ophthalmol 1984; 102: 891-4.
9 Weissman BA. Predicted changes in tear layer oxygen. Int Contact Lens Clin 1980; 5: 41-4.

10 Efron E, Carney LG. Oxygen tension beneath contact lenses under closed cyelids; human eye measurements. Am J Optom Physiol Opt 1981; 58: 806-9.

11 Manufacturer's specifications. Focus Contact Lenses, Northbridge, Berkhamstead, Herts HP4 1EH.

12 Brown N, Bron A. Recurrent erosion of the cornea. Br J Ophthalmol 1976; 60: 84-96.

Accepted for publication 25 June 1986. 